\title{
Tuberculosis in prisons
}

\author{
Possible links with HIV infection
}

A recent report from the United States has drawn attention to a dramatic increase in the incidence of tuberculosis in prisons in New York state - from 15.4 per 100000 between 1976 and 1978 to $105 \cdot 5$ in $1986 .^{\prime}$ High rates of tuberculosis in prisons have been reported before in the United States, ${ }^{23}$ but the new and disturbing feature is that in 1986 over half of the prisoners with the disease also had AIDS or were infected with HIV.' As the HIV state in the rest of the cases was not known the proportion of prisoners who were HIV antibody positive may well have been higher. In most of the patients tuberculosis was likely to be due to reactivation of earlier infection, but there was some evidence of transmission of the disease within prison.

The total number of new cases of tuberculosis in the United States increased between 1985 and 1986 for the first time in 30 years and undoubtedly this upsurge is related to the HIV epidemic. ${ }^{+}$The number of reported cases of AIDS in prisons in the United States more than doubled between 1986 and 1987 , but the proportion of the prison population infected with HIV is unknown.'

Britain now has the highest rate of imprisonment in western Europe $^{5}$ and its prisons are seriously overcrowded. ${ }^{67}$ The number of cases of tuberculosis reported in prisons in England and Wales in the past five years has shown no change, with only 14 cases in 1987 (J L Kilgour, personal communication). The number of prisoners infected with HIV is unknown-testing is undertaken only when clinically indicated and with informed consent (as in the general community) or at the prisoner's request. Only 240 prisoners with positive test results have been reported since central notification was started in 1985 (J L Kilgour, personal communication). This figure is an understatement of the incidence of infection, for prisoners know that if someone is identified as positive for HIV antibody the result may be discriminatory behaviour by both staff and fellow prisoners.

Future trends will depend on the degree of overlap between the populations infected with HIV and with the tubercle bacillus in the community and specifically in prisons. In England and Wales the highest rates of tuberculosis occur in the Indian, Pakistani, and Bangladeshi ethnic groups, with rates about 25 times higher than in white people. ${ }^{8}$ Other immigrant groups such as West Indians, Africans, Chinese, and Arabs have rates of about five to 10 times as high. ${ }^{8}$ In white people the highest rates occur in older men, and poor socioeconomic conditions and abuse of alcohol and drugs are well recognised risk factors. ${ }^{9}$ In 1983 over a quarter of all patients with pulmonary tuberculosis with positive sputum smears were white men aged 55 or over, and these are the main source of infectious cases in the population. ${ }^{10}$ The low rate of tuberculosis in the white population aged under 45 is likely to be related in part to the BCG vaccination programme, which was introduced in schools in 1953. BCG vaccination has never been used on a wide scale in the United States, and this difference in policy may be relevant to the relation between tuberculosis and HIV infection in the two countries.

In $1987,96 \%$ of the prison population of England and Wales were men and only $4 \%$ were aged 50 or over. "Most $(84 \%)$ of the male prisoners were white, and though some of the immigrant ethnic groups, particularly West Indians, were overrepresented, those from the Indian subcontinent made up about $3 \%$ of prisoners - the same proportion as in the general population. ${ }^{112}$ The initial medical assessment that all new prisoners undergo in England and Wales is unlikely to detect all cases of tuberculosis, and specific screening of high risk groups may be indicated.

Most of the patients with AIDS reported in Britain have been homosexual or bisexual men (PHLS Communicable Disease Surveillance Centre, unpublished data). Of the reported cases in women, however, a fifth were injecting drug users. The proportion of those reported to be infected with HIV who are injecting drug users is much higher-14\% of men and $55 \%$ of women. Most people known to be positive for HIV antibody are young adults, over $85 \%$ being aged $15-44$. Most people reported to have AIDS are of white ethnic origin, with less than $6 \%$ from other ethnic groups (N Gill, personal communication).

The incidence of HIV infection in prisons has been studied in several countries. In Spain, for example, where prisoners at risk are tested on entry, a quarter were positive. ${ }^{13}$ The extent of homosexual activity in prisons is impossible to assess, but 9\% of prisoners in England and Wales are admitted because of drug offences, though not all may be injecting drug users." The proportions are higher in women $(26 \%)$ than in men $(8 \%)$, particularly in the non-white ethnic groups $(49 \%$ and $22 \%$ respectively), and prostitution may be a further risk factor.

Our knowledge of the extent and spread of the HIV epidemic in the population is severely limited by the ethical restrictions on testing. These are likely to be even greater within the prison service. Routine HIV screening on admission to prison has been introduced in a few countries, but usually on a voluntary basis. ${ }^{13}$ Education is the most important approach to control of the HIV epidemic so far available. An active programme has been introduced in the prison service in England and Wales. It is difficult to predict whether Britain will follow the United States in experiencing an increase in tuberculosis associated with the HIV epidemic. There may be less overlap between the risk groups for tuberculosis and HIV infection, and BCG vaccination may have protected the age group currently most at risk of HIV infection. Nevertheless, the prison population is likely to be at particular risk of both infections, whether or not they occur together.

JANET H DARBYSHIRE

Member of Scientific Staff,

MRC Cardiothoracic Epidemiology Group,

Brompton Hospital,

London SW3 6HP

\footnotetext{
Braun MM, Truman BI, Maguire B, $\mathrm{ct}$ al. Increasing incidence of tuberculosis in a prison inmatc population. Association with HIV infection. FAMA 1989;261:393-7. Snider DE, Hutton MD. Tuberculosis in correctional institutions. FAMA 1989:261:436-7.

3 Stead WW. Undetected tuberculosis in prison. Source of infection for community at large. F. $111 \mathrm{~A}$ 1978:240:25+4-7.

4 Centers for Disease Control. Tuberculosis, final data-United States, 1986, M.MWR 1988;36

5 Smith R. Banging up Britain. Br Med J 1989;299:284.

6 Kilgour JL. The prison medical service in England and Wales: a commentary from the director of the prison medical service. Br.Med 7 1984;288:1603-5.

7 Smith R. Crisis upon crisis. Br Med f 1983;287:1705-8.

8 Medical Research Council Tuberculosis and Chest Diseases Unit. National survey of notification of tuberculosis in England and Wales in 1983. Br.Med $\mathcal{F}$ 1985;291:658-61.

Caplin M, Rehahn M. Alcoholism and tuberculosis. In: Vere DW, ed. Topics in therapeutics 4 London: Roval College of Physicians, 1978:136-49.

10 Medical Research Council Tuberculosis and Chest Diseases Unit. National survev of tuberculosis notifications in England and Wales in 1983: characteristics of disease. Tubercle 1987;68:19-32. Home (ffice. Prison statistics - England and Wales. London: HMSO, 1987.

12 Office of Population Censuses and Surveys. Labour force survev. London: HMSO, 1987. (Series L.FS No 7 .
}

13 Harding TW. AIDS in prison. L.ancet 1987;ii:1260-4. 